\title{
Surveillance of Washington OSHA Exposure Data to Identify Uncharacterized or Emerging Occupational Health Hazards
}

\author{
Don J. Lofgren, ${ }^{1}$ Carolyn K. Reeb-Whitaker, ${ }^{2}$ and Darrin Adams ${ }^{2}$ \\ ${ }^{1}$ Washington State Department of Labor \& Industries, Division of Occupational Safety and Health, Seattle, \\ Washington \\ ${ }^{2}$ Washington State Department of Labor \& Industries, SHARP Program, Olympia, Washington
}

\begin{abstract}
Chemical substance exposure data from the Washington State Occupational Safety and Health Administration (OSHA) program were reviewed to determine if inspections conducted as a result of a report of a hazard from a complainant or referent may alert the agency to uncharacterized or emerging health hazards. Exposure and other electronically stored data from 6890 health inspection reports conducted between April 2003 and August 2008 were extracted from agency records. A total of $515(7 \%)$ inspections with one or more personal airborne chemical substance samples were identified for further study. Inspections by report of a hazard and by targeting were compared for the following: number of inspections, number and percentage of inspections with workers exposed to substances above an agency's permissible exposure limit, types of industries inspected, and number and type of chemical substances assessed. Report of a hazard inspections documented work sites with worker overexposure at the same rate as agency targeted inspections (approximately $35 \%$ of the time), suggesting that complainants and referents are a credible pool of observers capable of directing the agency to airborne chemical substance hazards. Report of a hazard inspections were associated with significantly broader distribution of industries as well as a greater variety of chemical substance exposures than were targeted inspections. Narrative text that described business type and processes inspected was more useful than NAICS codes alone and critical in identifying processes and industries that may be associated with new hazards. Finally, previously identified emerging hazards were found among the report of a hazard data. These findings indicate that surveillance of OSHA inspection data can be a valid tool to identify uncharacterized and emerging health hazards. Additional research is needed to develop criteria for objective review and prioritization of the data for intervention. Federal OSHA and other state OSHA agencies will need to add electronic data entry fields more descriptive of industry, process, and substance to fully use agency exposure data for hazard surveillance.
\end{abstract}

Keywords chemical substance exposure, hazard surveillance, inspections, occupational health hazards, Occupational Safety and Health Administration, OSHA

Address correspondence to: Don J. Lofgren, Washington State Department of Labor \& Industries, Division of Occupational Safety and Health, 315 Fifth Ave. S., Suite 200, Seattle, WA 98104; e-mail: lofg235@lni.wa.gov.

\section{INTRODUCTION}

$\mathrm{O}$ ccupational hazard surveillance offers a means to prevent injury and illness in the workplace and presents a number of advantages over health surveillance. ${ }^{(1-7)}$ One of the main advantages is the more preventive nature of identifying hazards, rather than the resultant injuries or illnesses, which can lead to timely and effective intervention. Hazard surveillance has the potential to directly characterize industries and processes with workers at high exposure risk and to identify where prevention is required. Investigators are thus brought closer to the source of potential or existing injury or illness.

Surveillance of occupational exposure to chemical substances is a specific type of hazard surveillance, useful in the prevention of acute chemical effects and essential for the prevention of chemically induced chronic disease. ${ }^{(1,5)}$ A wellknown but perhaps underutilized source of chemical substance exposure data is the inspection files of the Occupational Safety and Health Administration (OSHA). A 1986 study by Froines et al. ${ }^{\left({ }^{(}\right)}$is one of the earliest examples of researchers utilizing OSHA exposure data to perform onetime surveys for chemical exposures in a limited number of industries. Froines et al. used federal OSHA exposure data to identify and characterize hazardous operations and industries with worker overexposure to airborne crystalline silica. A later survey used OSHA exposure data to characterize industries and processes associated with acute and chronic health risks of lead exposure. ${ }^{(9)}$ More recently, a study used exposure data from Washington State OSHA to identify health hazards, as well as common control and personal protective equipment problems among small business industries. ${ }^{(10)}$ However, OSHA exposure data are not known to be used by federal OSHA, state OSHA agencies, or any other researchers for hazard surveillance on an ongoing and systematic basis.

Numerous limitations of using OSHA agency exposure data in surveillance have been reported. ${ }^{(1,5,6,10,11)} \mathrm{A}$ primary limitation is that the framework for chemical substance sampling during inspections is driven by OSHA permissible exposure limits (PEL), which are frequently outdated and inadequate. 
Further limitations may include the lack of industrial hygiene inspections in certain industries due to policy, choices made in targeting, or lack of jurisdiction. Partly due to these limitations, more than one investigator has called for development of a comprehensive worker exposure database. ${ }^{(5,6,12)}$ However, no national, industry-inclusive exposure surveillance presently exists in the United States.

Despite these limitations, the exposure data collected and stored by federal and state OSHA agencies nevertheless have value for occupational illness prevention. OSHA agencies collect worker exposure data for common chemical substances used in different regions and in diverse industries, along with other data that may further characterize the exposure by type of control and work site. It is the systematic and ongoing nature of OSHA data collection that presents opportunities for hazard surveillance and timely interventions.

One of those opportunities may be in the surveillance of exposure data collected from inspections made as a result of a report of a hazard. The Occupational Safety and Health Act was created with a provision for employees and others to file complaints or reports of alleged hazards so that identified workplaces may be made safer. ${ }^{(13)}$ Reports of hazards may offer OSHA agencies an opportunity to inspect work sites and types of hazards not otherwise visited or identified. In contrast, inspections initiated by a targeted inspection program designed by agency staff are based primarily on evaluating known hazardous conditions. The worker exposure data collected at an individual work site inspected by a report of a hazard, if representative of a hazard common to a process or industry, may alert the agency to the need for a broader intervention beyond the individual site inspected.

This article reviews airborne chemical substance exposure data from Washington State OSHA compliance inspections to determine its usability for hazard surveillance. Report of $a$ hazard inspections are compared with targeted inspections to evaluate their value and to determine which is more effective in identifying hazardous processes and industries. The distribution of industries and chemical substances sampled are compared between the two inspection types. Further, we evaluated the usefulness of narrative information provided by the health inspectors that describes the hazardous condition, work process, and industry inspected. Finally, we make recommendations on how other state and federal agencies can make use of similar hazard surveillance methods to better identify risk and protect workers.

\section{METHODS}

$\mathrm{D}$ ata were extracted from existing inspection records of the Division of Occupational Safety and Health (DOSH), Department of Labor and Industries, the state OSHA agency for Washington. The State of Washington has administered the federally approved state OSHA program through the Washington Industrial Safety and Health Act (WISHA) since 1973. ${ }^{(14)}$ The agency serves employers and employees from both the private and public sectors and annually conducts approximately 9000 compliance inspections, of which about 1400 are industrial hygiene or health compliance inspections. Some of the predominant industries in Washington include agriculture, food processing, aerospace, forestry products, marine services, and information and biological technology.

The state agency initiates inspections as a result of complaints, referrals, targeting of high hazard work sites, and accidents. These compliance inspections are performed in accordance with the DOSH Compliance Manual and enforce the Washington Administrative Codes (WAC) in Title 296. ${ }^{(15,16)}$ Inspections are conducted in a similar, if not identical, manner to those done by federal OSHA. Most standards are the same as federal OSHA, but differences exist, with the state having broader scope and/or more stringent requirements. Assessment of health hazards by an industrial hygiene compliance inspector may include sampling for worker exposure to airborne contaminants, as necessary, to determine compliance with PELs and other occupational health standards. Chemical analyses of samples are performed by the Department's AIHA-accredited laboratory.

Completed inspection reports include a combination of electronically stored data and hard copies of notes, documents, photos, and other related inspection material. The electronic data were entered using the agency's WISHA Information Network (WIN) system that replaced the Washington State's OSHA Integrated Management Information System (IMIS) in April 2003. The WIN system presents screens organized for the primary purpose of documenting and writing violations of safety and health codes but also incorporates other data fields for tracking and statistical purposes. The electronic data are stored for at least 7 years.

\section{Data Extraction and Analysis}

Electronically stored data from 6890 health inspections conducted during the 60-month time period of April 2003 through August 2008, based on closing conference date, were extracted from the agency's WIN database. Extraction and analysis of the records for inspections with chemical sampling identified a total of $768(11 \%)$ inspections. Further extraction was performed, and excluded were 253 inspections where only area, bulk, and wipe samples were collected or physical hazards such as noise were sampled. A total of $515(7 \%)$ inspections having one or more personal airborne chemical substance samples with a recorded exposure value of zero or greater were identified for this study.

Selected data fields were extracted from the inspection records and included the following: inspection number, North American Industry Classification System (NAICS) two- and six-digit industry codes for the inspected company, reason for the inspection, closing conference date, business description, chemical substance, air contaminant exposure value, PEL, PEL type, ratio of exposure level to the PEL, sample type, job title and description, number of workers exposed, frequency of exposure, assessment of additive exposure, and whether a violation had been issued for lack of control or respirator 


\begin{tabular}{|c|c|c|c|}
\hline Reason for Inspection $^{A}$ & $\begin{array}{l}\text { \# Inspections } \\
\text { (\% of total) }\end{array}$ & 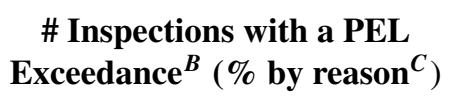 & $\begin{array}{c}\text { \# Inspections with Violation }{ }^{\mathrm{D}} \\
\left(\% \text { by reason }{ }^{C}\right)\end{array}$ \\
\hline Report of a hazard & $245(47)$ & $89(36)$ & $49(20)$ \\
\hline Complaint & $94(18)$ & $26(28)$ & $16(17)$ \\
\hline Referral & $133(26)$ & $55(41)$ & $31(23)$ \\
\hline Related & $18(3)$ & $8(44)$ & $3(17)$ \\
\hline Targeted & $236(46)$ & $83(35)$ & $61(26)$ \\
\hline SIC Code & $125(24)$ & $34(27)$ & $20(16)$ \\
\hline Local Emphasis & $44(9)$ & $24(55)$ & $21(47)$ \\
\hline Other & $60(12)$ & $24(60)$ & $20(33)$ \\
\hline Related & $7(1)$ & $1(14)$ & $1(14)$ \\
\hline Other: Follow-up, monitoring, and variance & 34 (7) & $14(41)$ & $3(9)$ \\
\hline Total & $515(100)$ & $186(36)$ & $113(22)$ \\
\hline
\end{tabular}

${ }^{A}$ See definitions in Methods section.

${ }^{B}$ Number of inspections with one or more workers found to have exposure greater than one of the state of Washington's permissible exposure limits (PEL), as listed in Washington Administrative Code 296-841.

$C$ "\% by reason" is the percentage of the listed value divided by the number of inspections in the same row, second column.

${ }^{D}$ Inspections with one or more workers found to have exposure greater than a PEL that resulted in a violation for lack of control, such as engineering control, or failure for a worker to wear a respirator.

use. ${ }^{(17)}$ Exposure values entered by the inspector were based on one or more samples and expressed as 8-hr time-weighted averages (TWA) or 15-min, short-term exposure averages (STEL) or on a single sample for a ceiling measurement. Additive mixtures were calculated in accordance with WAC 296-841-20005(5) and were added to the database by their related inspection number.

Data were managed using Microsoft Office Excel 2007 (Microsoft Corporation, Bellevue, WA). SAS version 9.2 (SAS Institute Inc., Cary, N.C.) was used for statistical analysis in Tables II and III. Monte Carlo simulation of Fisher's exact test $(n=100,000$ simulation) and chi square tests were used. Data rows having cells with zero values were not included in any statistical testing.

The data presented in Table IV are a subset from 9 of the 89 report of a hazard inspections having a PEL exceedance. The data are organized by year, followed by an inspection reference number in substitute for the actual inspection number. The original narrative texts were subject to minimal editing for clarity and presentation. The narrative business and job descriptions in electronic form are exclusive to the Washington State OSHA program at this time.

\section{Definitions}

\section{Report of a Hazard}

Inspections by report of a hazard were initiated as a result of a notice to the agency by individuals observing or otherwise learning of a hazard and are further defined as complaints, referrals, or related. Using Washington State OSHA definitions for the reason for an inspection (similar to federal OSHA), a Complaint is filed by an employee, their family member, or their representative. A Referral is from other individuals and includes physicians, ex-employees, or agency safety inspectors (agency referral) and includes reports obtained from the media. Included in the report of a hazard category are those inspections that are related by the fact that the employer was identified and inspected following an inspection of another employer based on a Complaint or Referral. Complaints and Referrals received by the agency go through a screening process that includes assessment of the seriousness of the hazard and credibility of the source.

\section{Targeted Inspections}

There were three different categories of targeted inspections that ran simultaneously during the study period. Washington State's Standard Industrial Classification (SIC) industry targeting was based on a modified federal OSHA plan that selected high-hazard industries defined by their four-digit SIC code and prior serious health violation rate. SIC code targeting of agriculture was included, whereas construction was excluded based on known difficulties in locating a specific employer's temporary work site. Local emphasis target programs were regionally based and identified potential high health hazard work sites by local knowledge, prior inspections, or modification of one of the health inspection's emphases established by federal OSHA. Other target inspections included "drive-by" sightings of targeted hazards, e.g., observation of dust from dry grinding of concrete and an emphasis for crystalline silica exposures. Related inspections are those identified and inspected as a result of a targeted inspection.

\section{PEL Exceedance}

A PEL exceedance occurred for an inspection when one or more workers at the inspected work site were found with 


\begin{tabular}{|c|c|c|c|c|c|}
\hline \multirow[b]{2}{*}{ NAICS Code ${ }^{D}$} & \multirow[b]{2}{*}{ NAICS Code Description } & \multicolumn{2}{|c|}{ \# Inspections ${ }^{A}$} & \multicolumn{2}{|c|}{$\begin{array}{c}\text { \# Inspections with a PEL } \\
\text { Exceedance }^{B, C}(\%)\end{array}$} \\
\hline & & $\begin{array}{l}\text { Report of } \\
\text { a Hazard }\end{array}$ & Targeted & $\begin{array}{l}\text { Report of } \\
\text { a Hazard }\end{array}$ & Targeted \\
\hline $31-33$ & Manufacturing & 96 & 120 & $37(39)$ & $42(35)$ \\
\hline 23 & Construction & 55 & 45 & $22(40)$ & $15(33)$ \\
\hline 42 & Wholesale Trade & 20 & 6 & $5(25)$ & $4(67)$ \\
\hline 81 & Other Services (ex. Public Administration) & 16 & 39 & $5(31)$ & $22(56)$ \\
\hline $44-45$ & Retail Trade & 15 & 12 & $5(33)$ & $10(83)$ \\
\hline $48-49$ & Transportation and Warehousing & 9 & 1 & $3(33)$ & $0(0)$ \\
\hline 56 & Admin. Support \& Waste Mgt \& Remediation Services & 8 & 4 & $6(75)$ & $1(25)$ \\
\hline 62 & Health Care and Social Assistance & 6 & 0 & 1 & 0 \\
\hline 54 & Professional, Scientific, and Tech. Serv. & 4 & 1 & 0 & 0 \\
\hline 51 & Information & 3 & 0 & 1 & 0 \\
\hline 71 & Arts, Entertainment and Recreation & 3 & 0 & 1 & 0 \\
\hline 92 & Public Administration & 3 & 0 & 0 & 0 \\
\hline 11 & Agriculture, Forestry, Fishing and Hunting & 2 & 4 & 1 & 1 \\
\hline 61 & Educational Services & 2 & 0 & 1 & 0 \\
\hline 53 & Real Estate and Rental and Leasing & 1 & 2 & 0 & 2 \\
\hline 21 & Mining & 1 & 0 & 0 & 0 \\
\hline 22 & Utilities & 1 & 0 & 0 & 0 \\
\hline 55 & Management of Companies and Enterprises & 0 & 1 & 0 & 1 \\
\hline 72 & Accommodation and Food Services & 0 & 1 & 0 & 0 \\
\hline 52 & Finance and Insurance & 0 & 0 & 0 & 0 \\
\hline Total & & 245 & 236 & $88(36)$ & $82(35)$ \\
\hline
\end{tabular}

${ }^{A}$ The distribution of industries for report of a hazard inspections compared to targeted inspections is significantly different (Monte Carlo estimate of Fisher's exact test, $\mathrm{p}<0.0001)$.

${ }^{B}$ Number of inspections with one or more personal samples exceeding the permissible exposure limit (PEL) listed in the Washington Administrative Code $296-841$. ${ }^{C}$ Within a given sector, the percent (rate) of PEL exceedances generated by report of a hazard inspections compared to targeted inspections is not significantly different (chi square and Fisher's exact test, $\mathrm{P}>0.2$ for all industries having at least one observation; tests not applied for industries with zero observations). ${ }^{D}$ North American Industry Classification System.

an exposure to an airborne chemical substance above its respective PEL. Exceedance ratios were calculated by dividing the reported exposure values by the respective PELs.

\section{Inspections with a Violation}

The types of code violations included in this study for a PEL exceedance were failure of the employer to use control such as engineering or administrative controls (WAC 296-84120010; also superseded WAC 296-62-7501-3-1) and failure of the employer to provide or employees to use respiratory protection (WAC 296-841-20015; also superseded WAC 29662-7103-1 and WAC 296-62-7103-3). ${ }^{(15)}$ Not included in the violation count were codes for the 12 chemical substances with comprehensive standards that utilized separate code numbers for lack of control or respiratory protection (e.g., standard for lead). The two types of violation selected for comparison were deemed the most critical and directly related to correcting worker exposure exceeding a PEL. Inspections with a PEL exceedance may not result in one of these violations but may result in other types of violations not reported here, e.g., lack of worker respirator fit testing.

\section{RESULTS}

\section{Types of Inspections and Number of Hazardous Work Sites}

The reason for an inspection with airborne chemical substance sampling, and the results with respect to worker exposure are shown in Table I. A report of a hazard was the reason for $47 \%$, or almost half, of the inspections. This percentage was similar to the $52 \%$ of all health inspections (with or without airborne chemical sampling) that were due to a report of a hazard (data not shown). Inspections by report of a hazard had nearly the same PEL exceedance rate as targeted inspections. The percent violations were largely similar as well between report of a hazard and targeted inspections. Among the types of targeted inspections, Local Emphasis and Other 


\begin{tabular}{|c|c|c|c|c|}
\hline \multirow[b]{2}{*}{ Chemical Substance $^{D}$} & \multicolumn{2}{|c|}{ \# Inspections ${ }^{A}$} & \multicolumn{2}{|c|}{ \# Inspections with a PEL Exceedance ${ }^{B, C}(\%)$} \\
\hline & Report of a Hazard & Targeted & Report of a Hazard & Targeted \\
\hline Silica, Quartz \& Cristabolite & 44 & 65 & $19(43)$ & $28(64)$ \\
\hline Acetone & 32 & 26 & 0 & 0 \\
\hline Toluene & 30 & 32 & $1(3)$ & $4(12)$ \\
\hline Total Particulate & 29 & 27 & $10(34)$ & $6(21)$ \\
\hline Petroleum Distillates & 25 & 22 & $3(12)$ & $2(9)$ \\
\hline Xylene & 25 & 20 & $1(4)$ & 0 \\
\hline Respirable Particulates & 24 & 24 & $5(21)$ & $3(13)$ \\
\hline Lead & 22 & 23 & $10(45)$ & $1(9)$ \\
\hline Carbon Monoxide (CO) & 22 & 17 & $8(36)$ & $2(12)$ \\
\hline Wood Dust, Soft, Hard, Cedar & 19 & 23 & $9(47)$ & $7(30)$ \\
\hline Ethyl Benzene & 17 & 17 & 0 & 0 \\
\hline Iron Oxide Fume & 17 & 10 & $6(35)$ & $1(10)$ \\
\hline N-Butyl Acetate & 16 & 17 & 0 & 0 \\
\hline Styrene & 11 & 6 & $2(18)$ & $5(83)$ \\
\hline Welding Fumes & 10 & 14 & $4(40)$ & $3(21)$ \\
\hline Formaldehyde & 10 & 10 & $1(10)$ & $1(10)$ \\
\hline Hexamethylene Diisocyanate (HDI) & 10 & 4 & $2(20)$ & 0 \\
\hline Methylene Chloride & 9 & 12 & $3(33)$ & $2(17)$ \\
\hline Isopropyl Alcohol & 9 & 2 & 0 & 0 \\
\hline Methylene Bisphenyl Isocyanate (MDI) & 8 & 27 & $3(38)$ & $18(67)$ \\
\hline Manganese Fume & 8 & 8 & $3(38)$ & 0 \\
\hline Arsenic \& Organic Compounds & 8 & 4 & 0 & 0 \\
\hline Chromium VI, Chromic Acid, Chromates & 7 & 5 & $3(43)$ & $2(40)$ \\
\hline 2-Butanone (MEK) & 7 & 4 & $5(71)$ & $1(28)$ \\
\hline Ethyl Alcohol & 6 & 6 & $1(17)$ & $2(33)$ \\
\hline Hexone (MIK) & 6 & 6 & 0 & 0 \\
\hline N-Butyl Alcohol & 5 & 7 & $1(20)$ & $1(14)$ \\
\hline Cadmium & 5 & 6 & $2(40)$ & 0 \\
\hline Cobalt & 5 & 6 & $1(20)$ & $1(17)$ \\
\hline Nickel, Metal \& Insoluble Compounds & 5 & 6 & 0 & 0 \\
\hline Aluminum Oxide \& Al & 5 & 4 & 0 & 0 \\
\hline Copper Fume & 5 & 1 & 0 & 0 \\
\hline 2-Butoxyethanol & 5 & 0 & 0 & 0 \\
\hline Octane & 4 & 6 & 0 & 0 \\
\hline Copper Dusts \& Mists & 4 & 3 & $1(25)$ & 0 \\
\hline Zinc Oxide Fume & 4 & 1 & 0 & 0 \\
\hline Asbestos (All Forms) & 4 & 1 & 0 & 0 \\
\hline
\end{tabular}

${ }^{A}$ The distribution of substances for report of a hazard inspections compared to targeted inspections are not significantly different (Monte Carlo estimate for Fisher's exact test, $\mathrm{P}=0.1998$ ).

${ }^{B}$ Number of inspections with one or more workers found to have exposure greater than the substance's State of Washington permissible exposure limit (PEL) as listed in Washington Administrative Code 296-841.

${ }^{C}$ Within a given substance, the percentage (rate) of PEL exceedances generated by report of hazard inspections compared to targeted inspections is significant only for lead (Fisher's exact $\mathrm{P}=0.016$ ). $\mathrm{P}>0.2$ for all other industries having at least one observation; test not applied for industries with zero observations.

${ }^{D} N$ ot shown are 88 other airborne chemical substances sampled with fewer than four inspections by a report of a hazard.

inspections had both PEL exceedance rates and violation rates that were greater than SIC driven inspections.

Report of a hazard inspections can be further categorized as non-agency-generated $(\mathrm{n}=159)$ or agency-generated $(\mathrm{n}=68)$ inspections (inspections related to complaints and referrals were excluded). Between inspections initiated by non-agency complainants and referents and those initiated by agency referents, the percentage of work sites found with a PEL exceedance was about the same, $34 \%$ versus $40 \%$, respectively. 


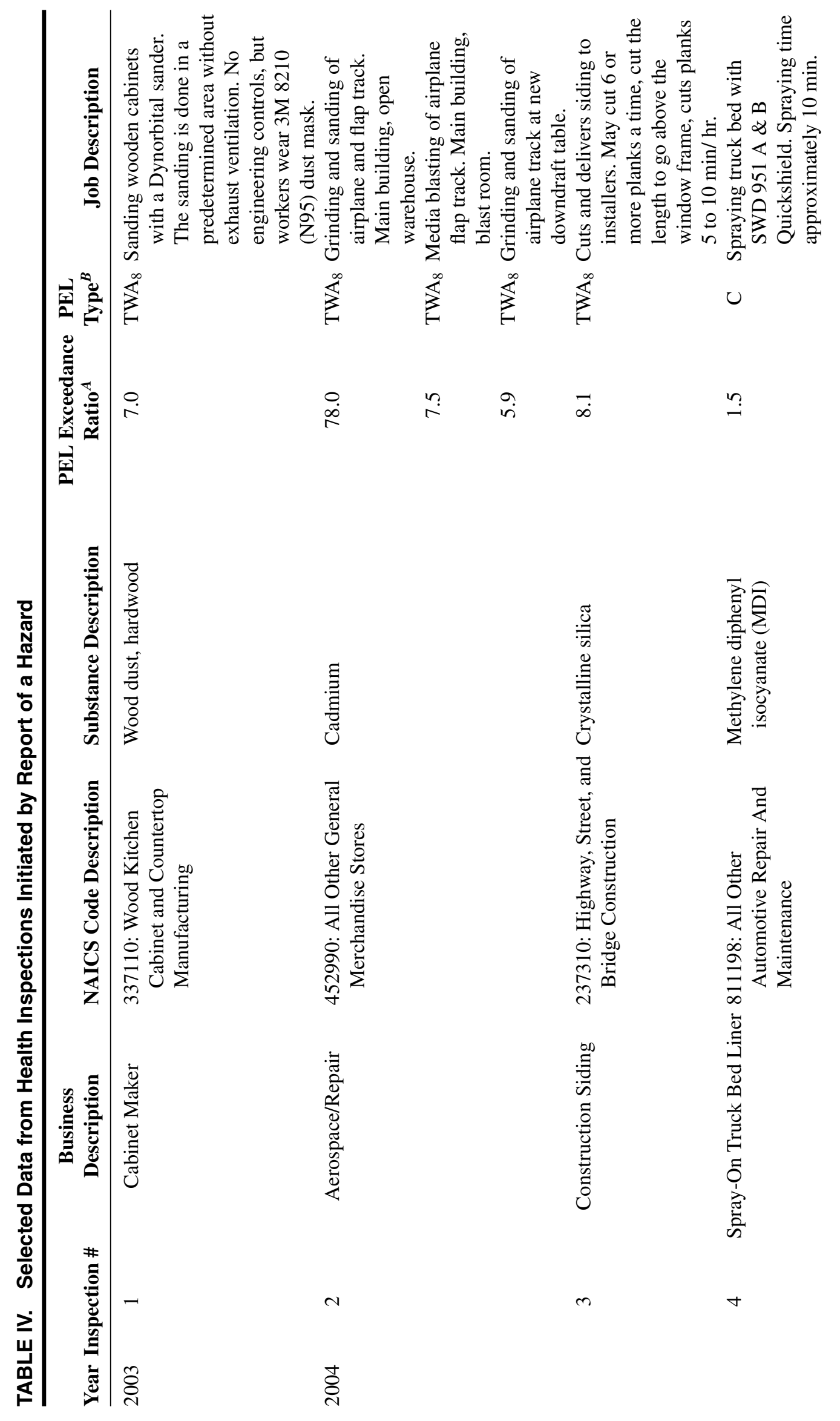



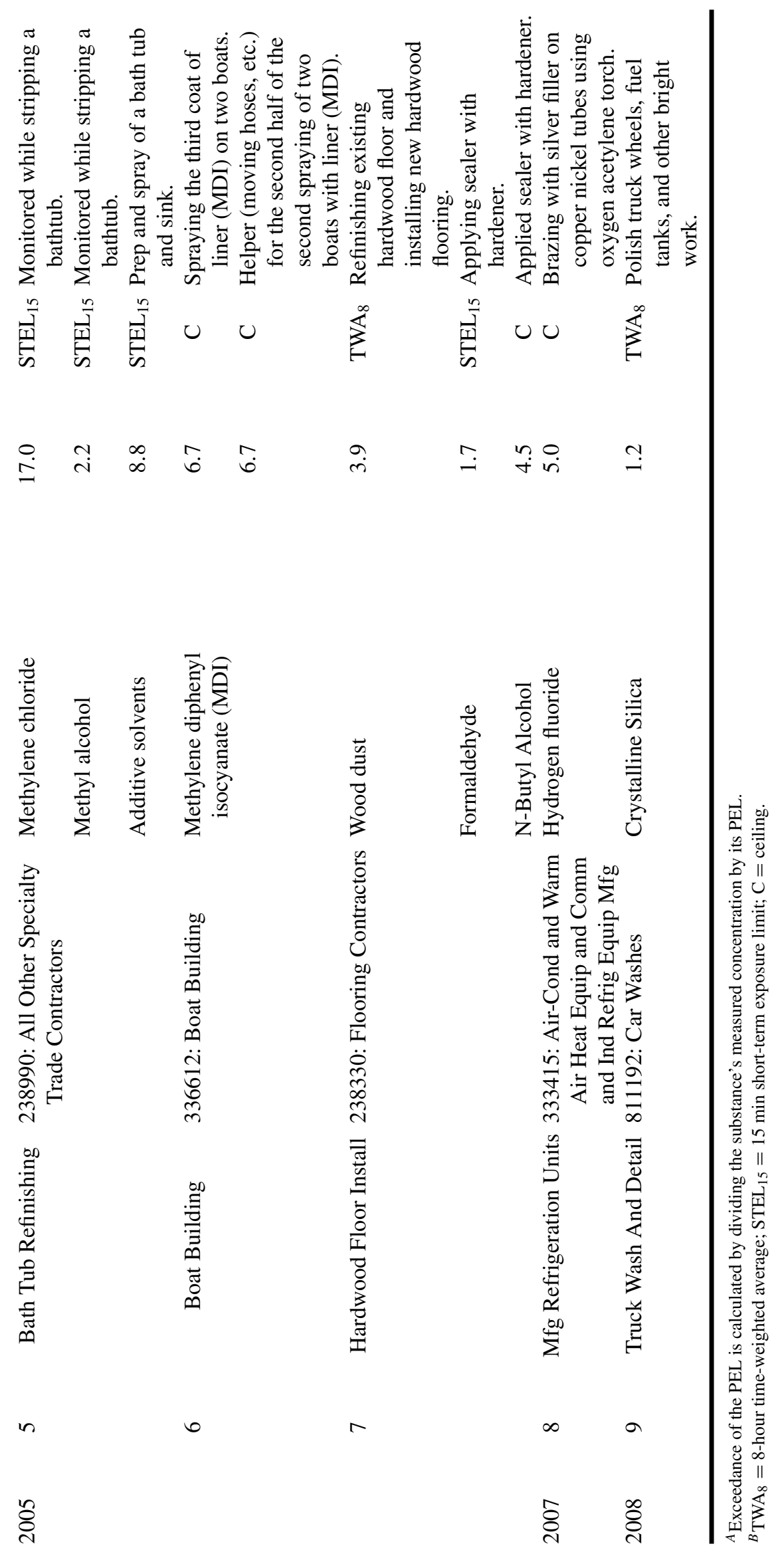


\section{Types of Industries Inspected}

The different economic sectors where inspections occurred, and the frequency at which sectors had an inspection with a PEL exceedance, were compared between the two main reasons for an inspection (Table II). Report of a hazard inspections were distributed across a wider range of economic sectors, whereas targeted inspections occurred predominantly in manufacturing $(\mathrm{p}<0.0001$; Monte Carlo estimate of Fisher's exact test). The percent PEL exceedances for inspections by report of a hazard compared with those for targeted inspections in a given economic sector were not significantly different (chi square and Fisher's exact test, $\mathrm{P}>0.2$ for all industries having at least one observation; tests not applied for industries with zero observations).

Differences in types of work sites inspected were further revealed using the more industry-specific six-digit NAICS codes for comparison. Inspections by report of a hazard occurred in 145 different industries of which 64\% (93) were unique to report of hazard. In contrast, targeted inspections occurred in just 109 industries of which 52\% (57) were unique to targeted. In construction, reports of a hazard inspection occurred in nine construction industries that were not visited through the targeted programs. Conversely, all of the construction industries visited through the targeted program were also visited through report of a hazard. In manufacturing, report of a hazard inspection occurred in 30 unique manufacturing industries that were not inspected through targeting. Conversely, the targeted inspections within manufacturing occurred in 37 unique industries not inspected by a report of a hazard and may be reflective of the targeting program's emphasis in manufacturing.

Examples of types of businesses found by reports of a hazard and not by targeting included Painting and Wall Covering Contractors (NAICS 238320) with three of nine inspected work sites with a PEL exceedance, Motorcycle Dealers (NAICS 441221) with two of four work sites with a PEL exceedance, and Offices of Dentists (NAICS 621210) with one of three work sites with a PEL exceedance.

\section{Chemical Substances Sampled}

Thirty-seven sampled chemical substances most often associated with report of a hazard inspections, along with comparative data from targeted inspections are shown in Table III. Twenty-four of the top 30 substances by frequency of inspection were the same for the two groups. Silica was number one for both. Methylene bisphenyl isocyanate (MDI) was ranked 14 for report of a hazard inspections and number three by frequency of targeted inspections most likely due to a special targeting emphasis held for truck bed lining that occurred during the time period.

Though there appears to be a trend for report of hazard inspections to have a higher rate of PEL exceedances compared with targeted inspections for individual substances displayed in Table III, no statistically significant difference was found, with one exception. Lead was the only substance to have a statistically different PEL exceedance ratio, with report of a hazard inspections having a higher exceedance ratio compared with targeted ( $\mathrm{p}=0.016$; Fisher's exact test). This difference may be due to the fact that 5 out of the 10 reports of a hazard were made based on elevated blood lead level (BLL) tests (data not shown). Elevated BLL tests can quantifiably document lead poisoning in the body and could be expected to be good indicators of elevated airborne lead levels.

A number of chemical substances were not above their PELs regardless of the reason for the inspection. Inspections with samples for acetone, ethyl benzene, n-butyl acetate, isopropyl alcohol, and 2-butoxyethanol reported no worker overexposure for these substances. This is a likely combination of the process at the work site and a relatively high PEL with respect to the chemical's volatility. These results contrast with the worker overexposures found for the more volatile and lower PEL chemical substances styrene, methylene chloride, and 2butanone (MEK).

Considering all chemical substances sampled, report of $a$ hazard inspections recorded 98 different types of substances of which $47(48 \%)$ were unique and not sampled in targeted inspections. Those substances unique to inspections by report of a hazard included methyl alcohol, with PEL exceedances for two of the three work sites inspected, and nitrous oxide. In contrast, targeted inspections recorded 78 different substances, with $27(35 \%)$ unique to targeting. Between the two reasons for an inspection, a total of 125 substances were sampled.

\section{PEL Exceedance by Industry for Inspections Initiated by Report of a Hazard}

Figure 1 uses report of a hazard inspection data to graphically show that the overexposures in these inspections ranged in chemical toxicity and occurred in a wide variety of industries. The figure combines Chemical Substance that workers were exposed to, NAICS two-digit codes for economic sector with reference to the more specific six-digit industry descriptions found in Appendix $\mathrm{A}^{(17)}$ and Average PEL Exceedance Ratio as an indication of the level of the hazard. Each bar represents data from one to three inspections, with a PEL exceedance for one of the chemical substances shown.

Displayed on the $\mathrm{z}$ or depth axis are 13 of the 98 chemical substances sampled during inspections initiated by a report of $a$ hazard. These substances were selected based on their greater percentage of work sites found with overexposure relative to the other substances (Table III). Eighty-one percent of the 89 report of a hazard inspections with a PEL exceedance (Table I) had at least 1 of these 13 chemical substances accountable for the exceedance. The 13 chemical substances listed on the $\mathrm{x}$ axis are dispersed across 60 different NAICS industries (six-digit level). Forty-eight of the NAICS industries had one inspection each, 11 industries had two inspections, and 1 industry had three inspections.

The level of exceedance of worker overexposure for an inspection is graphically shown on the y axis for a given NAICS code and substance. The exceedance ratios in most cases represent an average of those ratios for a single inspection. Where there was more than one inspection for 


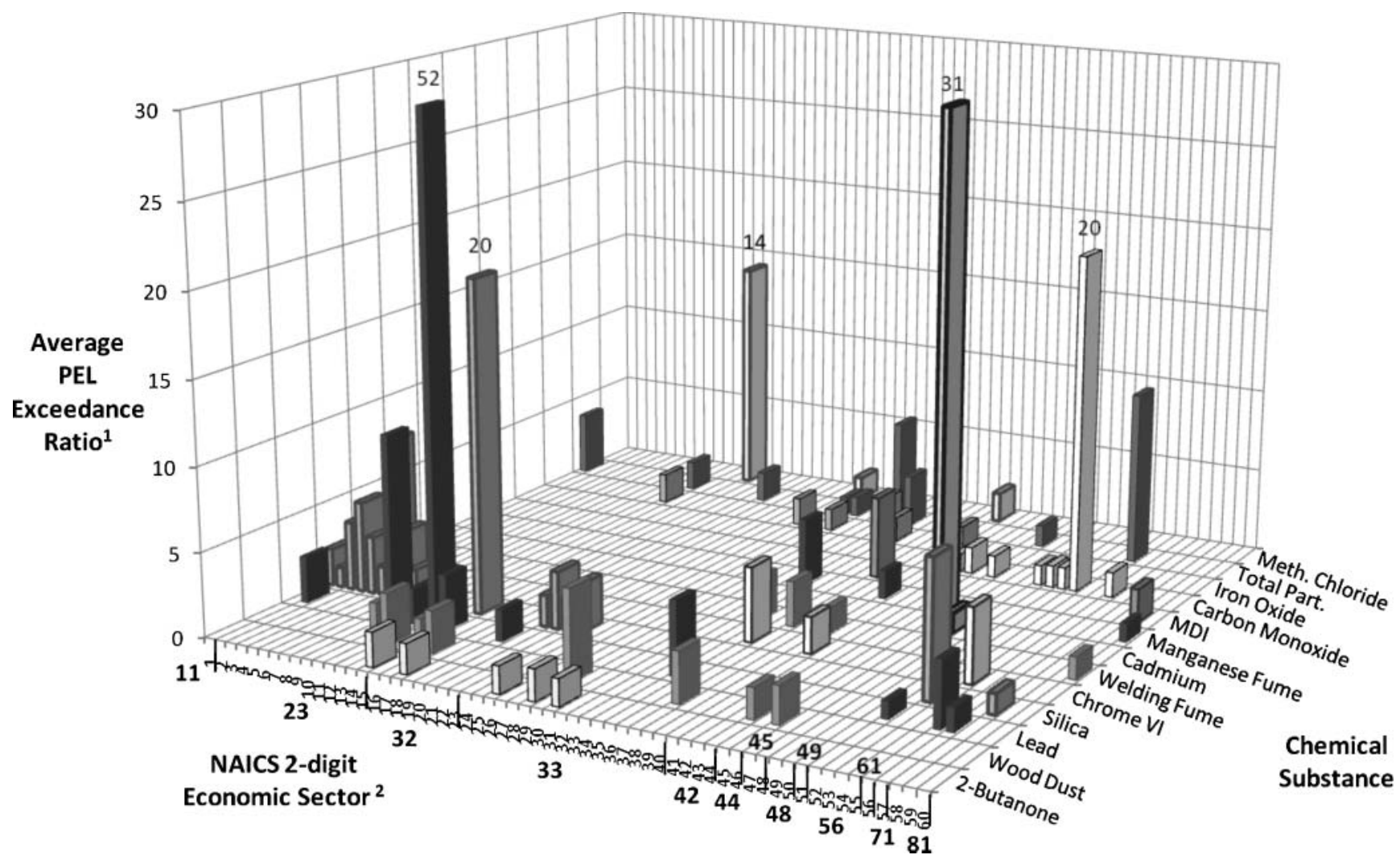

FIGURE 1. PEL exceedance ratio for select chemical substances by type of industry, as found on health inspections initiated by report of a hazard. Note 1: Exceedance ratios for the listed chemical substances were averaged and are shown for the inspected work site's NAICS code. The number of exceedance ratios for an inspection and substance varied from one to seven. A total of 72 inspections and 85 exceedance values obtained from 168 samples are represented in the figure. Silica includes values for both quartz and cristobalite. Note 2: The types of industries inspected were grouped by two-digit NAICS economic sectors with each row on the x-axis representing a unique six-digit NAICS industry not shown for clarity. See Table II for definitions of two-digit NAICS codes. Row numbers reference the specific six-digit NACIS code and description found in Appendix A. For the 60 different six-digit NAICS industries on the x-axis, 48 were inspected once in this chemical-only database, 11 were inspected twice, and one received three separate inspections.

a given NAICS and substance point, the exceedance ratio is an average of those inspections' average exceedance ratios.

\section{Sample Data from Inspections by Report of a Hazard}

Examples of data collected during inspections by report of $a$ hazard that may be used in surveillance for airborne chemical substance hazards are provided in Table IV. The unique narrative text for Business Description and Job Description provides critical detail beyond coding systems such as NAICS. Data from several inspections are displayed that may reveal existing health hazards not well characterized. For example, Inspection 2 indicates infrequent but extremely elevated exposure to a toxic metal, cadmium. These data suggest the need for further review to determine if like operations exist in the state and whether they have been inspected or otherwise known to have had implemented control. Inspection 8 provides a narrative job description indicating that brazing was associated with worker overexposure to hydrogen fluoride (HF). Without this added job description by the inspector, the specific type of operation associated with HF could go unnoticed. The HF exposure was remarkable as the agency has found few HF overexposures from welding or brazing. Three of five samples for HF exceeded up to five times the Ceiling PEL of $3 \mathrm{ppm}$. Further follow-up may determine this to be either a rare use of a fluoride containing material or it could be a potential hazard that inspectors do not currently recognize. Another example of a potentially uncharacterized hazard was found in Inspection 9. An airborne silica hazard not usually associated with truck wash and detail was revealed, and additional investigation was suggested. In contrast, Inspection 1 provides an example of an anticipated exposure to wood dust in a cabinet shop that may not warrant additional case review.

Other examples were found for potentially emerging health hazards. Inspection 3 reveals a relatively new siding product containing silica, which was being cut by a circular saw in an otherwise well-known industry. Inspection 4 informs on a well-known isocyanate product being used in a relatively new industry, and as available data suggested (not shown), a potentially small employer industry with attendant lack of hazard control. Both of these hazards, silica overexposure for workers installing fiber cement siding, and isocyanate 
overexposure for workers spraying bedliners on trucks, have been previously reported as emergent health hazards. ${ }^{(18,19)}$ Inspection 6 identifies isocyanates sprayed on boats, a parallel exposure to Inspection 4, and reveals a hazardous process in common with a different industry.

Another important observation from Table IV includes identification of multi-hazard exposures that occur within a specific industry and that can influence prioritization for intervention. Inspections 5 and 7 illustrate multiple exposures in bathtub refinishing and hardwood floor installation. Noise data, though not shown in the table, can be extracted from the inspection records to reveal an additional risk.

Further displayed are inspections with NAICS miscoding, as observed in Inspections 2 and 3, a result of errors in the business or insurance registration process. The miscoding in these two cases was discovered by review of the inspector's narratives in the business and job descriptions.

Additional data available but not shown in Table IV provide further information to help characterize industries and hazards. Exposure frequency, employee job title, exposure concentrations, code violations that may indicate missing control, additional exposure data for the same substance and task, and number of employees employed and exposed were available but not shown for conciseness. The inspection number can be used to reference hard copy information not electronically stored. Inspector and employer contact information are also available, allowing for further communication regarding the exposure, process, and industry.

\section{DISCUSSION}

A n opportunity for health hazard surveillance was explored with Washington State OSHA exposure data for airborne chemical substances gathered from inspections initiated by a report of a hazard. Health inspectors for the State of Washington OSHA program conducted 6890 inspections for the 60-month study period. Seven percent of these health inspections, or about 100 on an annual basis, resulted in personal sampling for airborne substances due to a report of a hazard. Federal and other state OSHA programs together perform a much greater number of health inspections on an annual basis and thus create an exposure data pool that can cast a significantly larger net for health hazards in a wider variety of regions, processes, and industries. Surveillance of this continuously updated data presents an opportunity for identifying emerging or uncharacterized health hazards on a national scale. This study of the State of Washington OSHA agency's worker exposure data has taken a step toward that goal.

Inspections initiated by a report of a hazard were both unique and valuable when compared with agency targeted inspections. Target programs devised by agency personnel are based primarily on inspecting for already known and characterized hazards. Examples include the targeting of the wood product industries for worker exposure to wood dust and noise, or of foundries with workers exposed to respirable crystalline silica. Report of a hazard inspections in contrast are reactive to reports from observers and occurred in industries and involved substances that were not found in the targeted inspections.

The two reasons for an inspection, overall, resulted in finding work sites with PEL exceedances at about the same rate (Table I). A closer look by individual economic sector or substance (Tables II and III) found no statistical difference for the rate of PEL exceedances between the two reasons, with the exception for lead having a greater rate of PEL exceedances for inspections by a report of a hazard. About one-third of the total types of substances sampled between the two reasons for an inspection were unique to inspections by a report of a hazard. The data established complainants and referents as a credible pool of observers capable of directing the agency to a significant number of work sites with airborne chemical substance hazards.

Further, examples of newly introduced health hazards as well as known work processes and materials with possibly under-recognized hazard potential were found in this data review for inspections by report of a hazard (Table IV). The narrative data entered by the inspectors illustrated the importance of including information more specific than sixdigit NAICS codes on the type of business, processes, and tasks at the inspected work site. In many cases, without this data it would be difficult to discern a potential emerging hazard from an existing well-known health hazard. Previously reported emergent health hazards for worker exposure to silica during fiber cement siding installation and to isocyanate exposure during spraying of truck bed lining, were found among the data (Inspections 3 and 4, Table IV). ${ }^{(10,18,19)}$ As was likely for these two cases, when a new process or industry begins to grow along with the number of exposed workers, it becomes more possible that a report of a hazard will be filed and an OSHA inspector responds.

A periodic review of the type of data presented here by an analyst with industrial hygiene experience offers an opportunity to identify types of work sites and processes with chemical substance hazards. Through a routine surveillance program, an analyst could compare previous years of data to determine if there were trends, review the narrative comments for text indicating a possible new product or process, or recognize something out of the ordinary that needed additional research. More information on the product or process could be obtained from a supplier, industry or union representative, the inspector, or the employer contacts, as the employer may be identified from the electronic data. Additional research in each case may indicate that like work sites or like processes may have uncontrolled exposures warranting intervention. Surveillance of inspections by report of a hazard does offer OSHA agencies an opportunity to discover and more systematically address airborne chemical substance hazards different from targeting programs and that may be uncharacterized or emerging.

\section{Additional Observations}

Two observations from the data, but unrelated to the study's goals, are noteworthy. Targeting of inspections by the agency's local emphasis program appeared to be twice 
as effective as SIC code targeting in finding work sites with PEL exceedances and, if true, suggests a shift in resources by the agency. However, more analysis is needed, as other variables not part of this study need to be considered. The other observation is that a small number of chemical substances appeared responsible for a majority of the work sites with PEL exceedances: 2-butanone, cadmium, carbon monoxide, chrome VI, iron oxide, lead, manganese fume, methylene chloride, methylene diphenyl isocyanate (MDI), crystalline silica, total particulate, welding fume, and wood dust. These 13 chemical substances selected for Figure 1 accounted for $81 \%$ of the report of a hazard inspections (72 of 89) with a PEL exceedance. The same 13 chemical substances accounted for $84 \%$ of the targeted inspections (70 of 83) with a PEL exceedance. There were instances of inspections having more than 1 of the 13 substances with a PEL exceedance, e.g., the PEL for total particulate was exceeded in 12 inspections of which 6 also had either iron oxide, welding fume, or silica PEL exceedances.

The data simply may reflect the limitations of using OSHA inspection data for surveillance or, on the other end of speculation, provide evidence that for workers in the State of Washington, fewer than 15 chemical substances are the primary contributors to the risk of disease presented by the 600 chemical substances listed in the state's PEL table. Further research is warranted.

\section{Limitations of OSHA Agency Exposure Data for Hazard Surveillance}

Several limitations exist for using OSHA agency exposure inspection data in health hazard surveillance; a number of them have been previously identified. ${ }^{(1,6,10,11)}$ Currently, OSHA and most state OSHA agencies do not have systems capable of electronically capturing the narrative information that more definitively describes industry, process, and exposure. In Washington, it is the state's unique intermediary WIN database that allows for the collection of narrative information so critical in describing the context of the exposure. Federal OSHA has plans to improve their collection of inspection data in electronic form in a new program called OSHA Information System (OIS), which is expected to replace the Integrated Management Information System (IMIS) in approximately 2010.

Another limitation to the IMIS system is that substances without a PEL, perhaps less likely to be recognized and sampled, cannot be entered into OSHA's current IMIS database because those substances have no IMIS chemical substance code. Chemical substance coding in inspection reports is presently limited to a fraction of the chemical substances to which workers are potentially exposed. OSHA agencies list airborne PELs for approximately 600 substances, whereas the EPA's chemical inventory reports approximately 62,000 commercial chemicals in the United States. ${ }^{(20-22)}$ Federal and state OSHA inspection databases, including the State of Washington's, need to include substances without PELs so that new or unusual exposures can be documented and subject to surveillance.
Certain substances also may not be sampled by inspectors as often as others. For example, asbestos was sampled in just five inspections and each without a PEL exceedance. The lack of sampling for airborne asbestos by inspectors likely reflects a standard that also allows enforcement without proof of a PEL exceedance. Similarly, the OSHA-enforced and EPAmandated use of PPE during pesticide application allows an inspector to proceed, when warranted, directly to a citation without sampling. There were six inspections in agriculture having recorded values for nonpesticide airborne substances, two for report of a hazard, and four for targeted. The reasons for few nonpesticide substance samples in agriculture are unclear.

Reliance on individuals to observe and report health hazards to the agency may also introduce biases in the types of work sites or hazards reported. Some industries may have a culture that discourages agency notification. Another type of bias is that observers may be more likely to file reports for hazards that affect the senses (e.g., visible dust containing silica or the odor of solvents) and less likely to identify chronic hazards. ${ }^{(6)}$ About two-thirds of the chemical substances listed in Table III may be detected either by odor or by sight about their respective PEL. It is possible that the chemical substance sampled during a report of a hazard inspection was not part of the hazard specifically alleged by the complainant or referent. This study did not determine correlation between the alleged hazardous substance and the documented overexposures. The issue is moot if enough complainants and referents nevertheless help the agency identify health hazards needing intervention.

Finally, this study did not examine differences in substance toxicity or likelihood of an injury or illness between types of inspections. The most frequently inspected substances were similar, however, between the two types of inspections. For purposes of the hazard surveillance proposed, the goal is to identify workers at risk of serious illness from exposure to airborne chemical substances.

\section{Additional Steps}

Further consideration needs to be given on how best to organize, review, evaluate, and prioritize the data for intervention in identified processes and industries. The qualitative aspect relies on occupational health specialists making judgments from personal knowledge and experiences, and this could be challenging given the vast diversity and complexity of processes and industries, although if performed conservatively and followed by additional research, it could prove effective.

A more quantitative approach could be developed that would include objective criteria for sorting and ranking of the data. Prioritization could be based on substance toxicity and exposure level, followed by research on the number of like work sites or employers, average number of employees per work site, numbers of workers exposed, and possible level of control among the work sites. Pilot targeting or interventions could be established to obtain further information on the hazard and level of control being used within the industry being assessed. The collected information would be used to identify 
new or emerging processes or industries with the most serious health hazards needing intervention.

The development of a surveillance system for OSHA data has implications beyond the context of the airborne chemical data described here. Surveillance of other types of health hazards is possible (e.g., bloodborne pathogen exposure and engineering controls for sharps). ${ }^{(10)}$ Further, the number of OSHA safety inspections greatly surpasses the number of health inspections. Safety inspections identify physical hazards, such as lack of eye protection, machine guarding, or fall protection. Hazard surveillance of safety inspection data along with injury data may likewise prove useful to identify equipment, processes, or industry sectors needing intervention.

\section{CONCLUSION}

$\mathrm{E}^{\mathrm{x}}$ xposure data and other data from inspections initiated as a result of a report of a hazard found that surveillance of the data could help identify uncharacterized or emerging health hazards that may exist in like work sites or industries. Inspections by report of a hazard from complainants and referents identified worker overexposures to a number of toxic airborne substances in a wide variety of industries, including substances and industries not inspected by a targeting program. Examples of inspection data showing narrative information on process and business description more specific than NAICS codes demonstrated how critical the narrative data were to identifying new hazard conditions. Previously identified emerging health hazards were found among the data and support the surveillance of exposure data collected during inspections initiated as a report of a hazard. Finally, additional work is needed to develop criteria for objective review and prioritization of the results.

\section{RECOMMENDATIONS}

$\mathrm{W}$ e recommend that surveillance of inspection data be considered at the state and national levels by OSHA agencies, the National Institute for Occupational Safety and Health (NIOSH), and other organizations seeking to prevent occupational injury and illness. Further, the current OSHA inspection reports and IMIS electronic tracking systems should be expanded so that hazard surveillance of exposure data may be realized on a national scale. There is a need to electronically record exposure to non-coded chemical substances as these substances inherently may represent emerging hazards. In addition, electronic capture of narrative fields that describe job process and industry type are needed. A periodic review of continually updated inspection data, in the form of hazard surveillance, can help OSHA agencies identify hazardous processes and industries that may need intervention.

\section{ACKNOWLEDGMENTS}

$\mathrm{W}$

e thank Barbara Silverstein and Dave Bonauto of the SHARP program, and Eric Tabb for review of this manuscript. The contents are solely the responsibility of the authors and do not necessarily reflect the views of the reviewers or the State of Washington.

\section{REFERENCES}

1. Froines, J.R., C.A. Dellenbaugh, and D.H. Wegman: Occupational health surveillance: A means to identify work-related risks. Am. J. Pub. Health 76(9):1089-1096 (1986).

2. Sundin, D.S., and T.M. Frazier: Hazard Surveillance at NIOSH. Am. J. Pub. Health 79(Suppl.):32-37 (1989).

3. Baker, E.L., J.M. Melius, and J.D. Millar: Surveillance of occupational illness and injury in the United States: Current perspectives and future directions. J. Pub. Health Pol. 9:198-221 (1988).

4. Froines, J.R.: Worksite inspection and the control of occupational disease: The OSHA experience. Ann. N.Y. Acad. Sci. 572:176-183 (1989).

5. Halperin, W., and E.L. Baker (eds.): Public Health Surveillance. New York: Van Nostrand Reinhold, 1992.

6. Froines, J.R., D. Wegman, and E. Eisen: Hazard surveillance in occupational disease. Am. J. Pub. Health 79(Suppl.):26-31 (1989).

7. Kauppinen, T., and J. Toikkanen: Health and hazard surveillanceNeeds and perspectives. Scand. J. Work Environ. Health 25(Suppl. 4):6167 (1999).

8. Froines, J.R., D.H. Wegman, and C.A. Dellenbaugh: An approach to the characterization of silica exposures in U.S. industry. Am. J. Ind. Med. 10:345-361(1986).

9. Froines, J.R., S. Baron, D.H. Wegman, and S. O'Rourke: Characterization of the airborne concentrations of lead in U.S. industry. Am. J. Ind. Med. 18:1-17 (1990).

10. Lofgren, D.J.: Results of inspections in health hazard industries in a region of the State of Washington. J. Occup. Environ. Hyg. 5:367-379 (2008).

11. Lofgren, D.J.: Targeting industries and worksites for OSHA health inspections. Appl. Occup. Environ. Hyg. 11:448-456 (1996).

12. Boiano, J.M., and R.D. Hull: Development of a national occupational exposure survey and database associated with NIOSH hazard surveillance initiatives. Appl. Occup. Environ. Hyg. 16:128-134 (2001).

13. "Occupational Safety and Health Act of 1970." Title 29, Labor, United States Code, Section 655.8.f.

14. "Washington Industrial Safety and Health Act." Revised Code of Washington Title 49, Chapter 49.17 RCW. 2006.

15. Department of Labor and Industries: DOSH Compliance Manual. Division of Occupational Safety and Health, Tumwater, Wash., 2006.

16. "Washington Administrative Code Title 296." [Online] http://www.lni. wa.gov/Safety/Rules/Find/WACNumber/default.htm (Accessed November 7, 2009).

17. "NAICS Code Look-Up." [Online] Available at http://www.naics. com/search.htm (Accessed November 7, 2009).

18. Lofgren, D.J., D.C. Johnson, and T.L. Walley: OSHA compliance issues-silica and noise exposure during installation of fibercement siding. J. Occup. Environ. Hyg. 1:D1-D6 (2004).

19. Lofgren, D.J., T.L. Walley, P.M. Peters, and M.L. Weis: MDI exposure for spray-on truck bed lining. Appl. Occup. Environ. Hyg. 18:772-779 (2003).

20. "Air Contaminants." [Online] Available at http://www.osha.gov/pls/ oshaweb/owadisp.show_document?p_table=STANDARDS\&p_id=9991 (Accessed November 7, 2009).

21. "Airborne Contaminants." PELs, Washington Administrative Code 296-841-200, Table 3, January 1, 2004. [Online] Available at http://www.lni.wa.gov/WISHA/Rules/AirborneContam/default.htm (Accessed November 7, 2009).

22. Environmental Protection Agency (EPA): Toxic Substance Control Act (TSCA) Chemical Substances Inventory: Revised Inventory Synonym and Preferred Name File and SARA Title III. Washington, D.C.: EPA, Office of Pollution, Prevention, and Toxics, 2009 


\section{APPENDIX A}

TABLE 1A. NAICS Codes and Industry Description for Figure 1

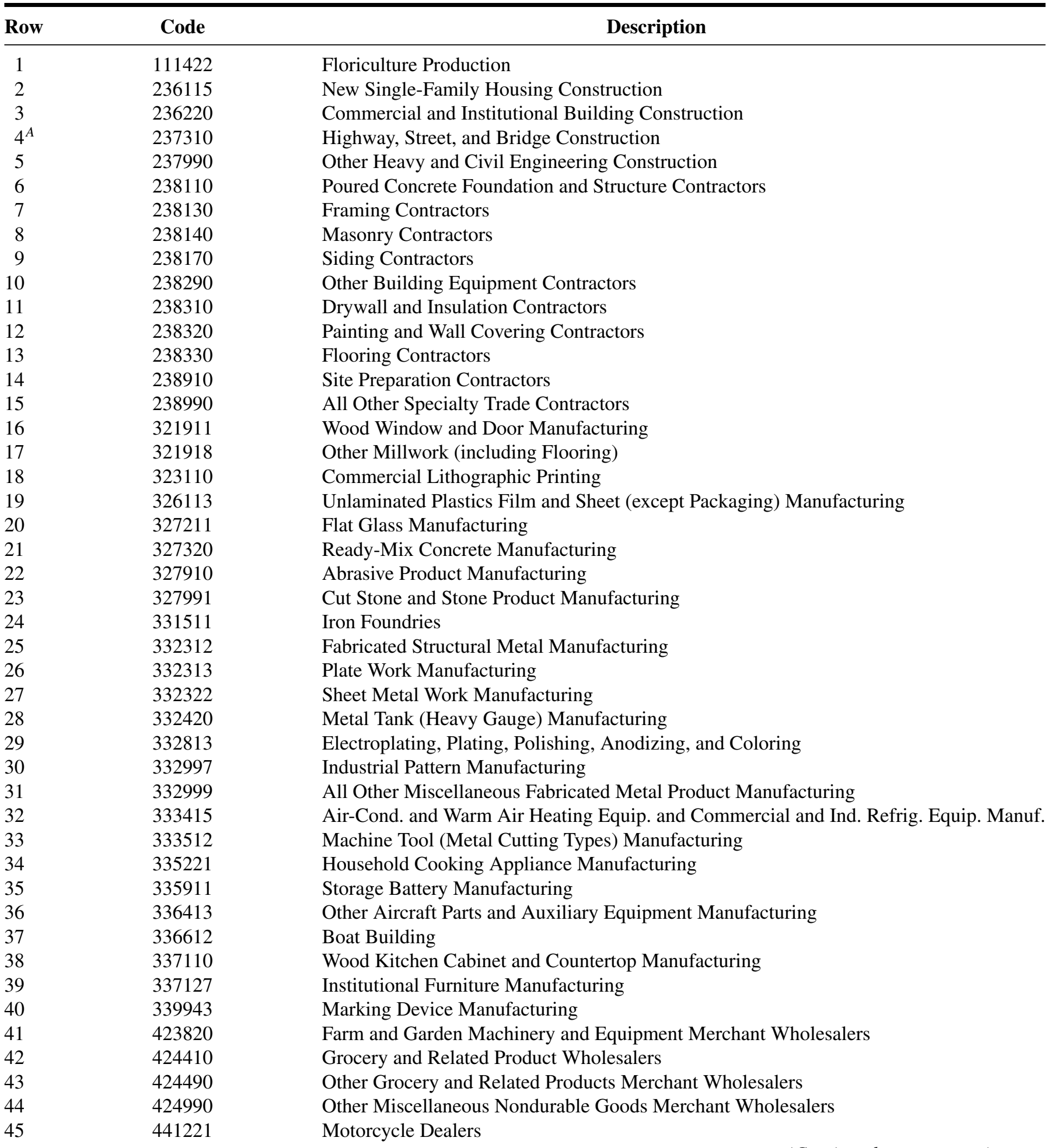

(Continued on next page) 
TABLE 1A. NAICS Codes and Industry Description for Figure 1 (Continued)

\begin{tabular}{lll}
\hline Row & Code & \\
\hline 46 & 442110 & Description \\
$47^{B}$ & 452990 & Furniture Stores \\
48 & 453998 & All Other General Merchandise Stores \\
49 & 484230 & Specialized Freight (except Used Goods) Trucking, Long-Distance \\
50 & 488510 & Freight Transportation Arrangement \\
51 & 493110 & General Warehousing and Storage \\
52 & 561720 & Janitorial Services \\
53 & 562910 & Remediation Services \\
54 & 562920 & Materials Recovery Facilities \\
55 & 562998 & All Other Miscellaneous Waste Management Services \\
56 & 611519 & Other Technical and Trade Schools \\
57 & 713990 & All Other Amusement and Recreation Industries \\
58 & 811192 & Car Washes \\
59 & 811198 & All Other Automotive Repair and Maintenance \\
60 & 811310 & Commercial and Ind. Machinery and Equip.(except Auto. and Electronic) Repair and Maint. \\
\hline
\end{tabular}

${ }^{A}$ Work site for data in Row 4 of Figure 1 was discovered to have been assigned the wrong NAICS code in agency records. Correct NAICS code and description is 238170, Siding Contractors.

${ }^{B}$ Work site for data in Row 47 of Figure 1 was discovered to have been assigned the wrong NAICS in agency records. Correct NAICS code and description is 336411, Aerospace Product and Parts Manufacturing. 